\title{
A escrita "literária" da narrativa na escola: condições e obstáculos
}

\section{"Literary" writing of narratives at school: conditions and obstacles}

\author{
Catherine Tauveron ${ }^{1}$
}

\begin{abstract}
RESUMO
O artigo apresenta o quadro conceitual de uma pesquisa-ação, "A escrita literária da narrativa na escola", realizada pelo Instituto Nacional de Pesquisa Pedagógica de Paris. Esta pesquisa, que se seguiu a outra sobre a leitura literária na escola, articula leitura literária e escrita literária. Ela postula a necessidade de estabelecer uma relação estética entre o aluno que escreve e seus leitores em classe. Há uma relação estética quando o primeiro, adotando uma postura de autor, se sente autorizado na comunidade da classe a desenvolver uma intenção artística singular e quando os segundos, abandonando seu olhar "ortopédico", consentem em ler os textos de seus pares como eles leriam os textos literários, adotando uma atenção estética suscetível de tornar a intenção artística singular manifestada e de fazê-la frutificar. Expõem-se em seguida as condições pedagógicas concretas para que aconteça a relação estética postulada. Em um segundo momento, apoiamo-nos em resultados de outra pesquisa, descritiva e qualitativa, sobre as representações (de escrita, das competências dos alunos), os critérios de avaliação e de aptidão à escrita/reescrita de 30 professores "comuns" no ensino fundamental e médio. A partir dos dados recolhidos são pontuados os elementos que causam obstáculo à legitimação da postura do autor em classe e à implementação das proposições da ação anterior, obstáculo o qual convém levar em conta no quadro de uma ação de formação.
\end{abstract}

Palavras-chave: narrativa de ficção; postura de autor; intenção artística; atenção estética; ortodoxia/heterodoxia.

DOI: $10.1590 / 0104-4060.36286$

1 Universidade da Bretanha Ocidental. Brest, France; 3 rue des Archives, 29238. 


\begin{abstract}
The conceptual background of an action-research, "Literary" writing of narratives at school" undertaken at the National Institute for Pedagogical Research in Paris is presented. This study, which followed another one about literary reading at school, links literary reading to literary writing and proposes the necessity of establishing an aesthetic relation between the student writer and readers from the class. There is an aesthetic relation when the student writer, as an author, feels authorized by the classmates to develop a singular artistic intention and when the student readers who are devoid of an "orthopedic" perspective consent to read the texts of peers as if reading literary texts, adopting an aesthetic attention susceptible to reveal and bear singular aesthetic intention. The concrete pedagogical conditions that foster aesthetic relations are postulated. At a second moment, the elements that set up obstacles to both the legitimacy of the author attitude in class and the implementation of the previous action are presented, supported by a previous descriptive and qualitative research on the representations of writing and of student skills, the evaluation criteria and the writing/rewriting skills of 30 "ordinary" elementary and high school teachers. Such obstacles should be considered in continuous educational actions for teachers.
\end{abstract}

Keywords: fictional narrative; author attitude; artistical intention; aesthetic attention; orthodoxy/heterodoxy.

Há tempos tem-se postulado que os alunos da escola primária não podiam realizar uma leitura interpretativa, ter acesso a uma dimensão simbólica dos textos literários, construir seu modo de entender e se deleitar. Em uma pesquisa-ação anterior, "A leitura literária na escola" (TAUVERON, 1999, 2002), feita no INRP ${ }^{2}$, nós dedicamos nossos esforços para demonstrar a impertinência do postulado e constatar com satisfação a introdução do conjunto de nossas proposições de ação nos programas oficiais franceses para a escola. Apostando sempre na inteligência e na sensibilidade dos alunos, na pesquisa-ação apresentada aqui, igualmente realizada no INRP, e se debruçando sobre a escrita literária da narrativa ${ }^{3}$, com suporte de umas trinta turmas, nós acreditamos ser necessário esclarecer outra ideia concebida: aquela que coloca que os alunos da escola primária, se eles são a rigor "criativos", não seriam considerados como criadores já que inaptos a formular um projeto estético consciente (eles não teriam mais que o prazer involuntário da escrita). Nós pudemos observar,

2 Instituto Nacional de Pesquisa Pedagógica no 30 339, Direção do programa 3, Unidade de pesquisa Francês, "Didática da leitura literária da narrativa à escola. Ciclos 2 e 3".

3 Pesquisa 35025c, intitulada "A escrita literária da narrativa à escola: quais saberes para quais saber-fazer? Aproximação sistemática e tática". 
no curso de três anos de pesquisa, sem nos deixar levar pelo "valor" dos textos produzidos, que os alunos da escola primária podiam adotar uma postura de autor (que trataremos por um termo conhecido como "ethos discursivo") desde que certas condições didáticas ${ }^{4}$ estivessem reunidas. São estas as condições (das quais o distanciamento evocado na leitura literária faz parte), assim como a concepção subjacente da escrita, que pretendemos apresentar em linhas gerais no primeiro momento que se segue. Em um segundo momento, nós apresentaremos algumas constatações produzidas em uma pesquisa descritiva posterior, feita no IUFM (Instituto Universitário de Formação de Mestres) de Rennes, com o apoio financeiro do INRP, intitulada "Práticas do rascunho em literatura". Mais precisamente nós selecionaremos alguns obstáculos maiores à aplicação concreta de nossas proposições anteriores pelos professores "comuns", obstáculos relativos às suas representações da escrita e do sujeito escolar escritor, suas práticas de avaliação ditadas pela sua concepção do "bom" texto do aluno, as quais convém levar em conta em um projeto de formação.

\section{Uma pesquisa-ação sobre a escrita literária na escola}

\section{Do aluno-escritor ao aluno-autor}

O léxico didático possui apenas uma palavra para designar o leitor, seja ele aprendiz ou expert. A partir do momento em que ele está engajado no processo, o aluno é leitor. Por outro lado, o mesmo léxico didático distingue produtor de textos do autor e mais ainda do escritor. Quando o ato léxico é visto como um contínuo, o ato de escrever é visto na prática como um percurso separado: o aluno, isolado do escritor por uma fronteira intransponível, é confinado no espaço da "escripção", quando não da "escrivinhatura": um trabalhador ou um capinador forçado da língua, ele não estaria apto a alcançar o status de cultivador da língua, construir seu estilo próprio, que Barthes (1972) concebe precisamente como um "fenômeno germinativo", "uma língua autárquica que mergulha suas raízes na mitologia pessoal e secreta” de seu utilizador, e muito menos a construir um espaço imaginário próprio. Para tanto, imitar os gestos do escritor (mas sem jamais explicitar o que podem ser estes gestos) é o que se solicita por meio das instruções dadas, em uma injunção paradoxal sempre

4 No espaço francófono, foi chamada pesquisa em didática (da língua materna, por exemplo) toda pesquisa que se interessa pelo ensino e a aprendizagem dos conteúdos da disciplina. 
desestabilizadora. O pequeno aluno não se engana, ele se sente a maior parte do tempo inseguro desde o momento em que ele deve escrever. Por que, para que e o que ele deve escrever? Ele com frequência ignora, ou mais exatamente ele faz suposições, sempre arriscadas, sobre o que o professor espera dele (enquanto que o professor frequentemente não sabe ele mesmo o que espera precisamente quando ele apresenta uma instrução: ele realiza a tarefa antes de impô-la, como ele o faz, sem dúvida, em outros domínios escolares?). Ele sabe que seu texto, de alguma forma falho, será submetido a um olhar "ortopédico", recolocado nas normas, reenquadrado, colocado em desordem para se submeter à representação implícita do professor sobre "como deveria ser este texto" (representação que se apressa para partilhar com seus leitores pares, por vezes mais "ortopedistas" que "ortopedagógicos"). Submetido à avaliação/correção coletiva, o texto do aluno não lhe pertence mais, se é que em algum momento ele lhe pertenceu.

Fez-se necessário certo tempo, o tempo de várias pesquisas sobre a leitura, abrangendo mais o ensino fundamental que o médio, para que se viesse a passar a observar as capacidades interpretativas dos jovens alunos (observáveis desde o maternal), para entender e fazer entender "seus textos singulares de leitores" (BAYARD, 1998). Em outros termos, fez-se necessário um tempo para reconhecer os sujeitos leitores no sujeito escolar, até aqui concebido na escola como um sujeito cognitivo com capacidades indiferenciadas e limitadas (sujeito apenas capaz de responder com uma única voz às questões impostas, incapaz de traçar um caminho no texto sem trilhas previamente balizadas). Nós desejamos que, simetricamente, se queira examinar a possibilidade teórica de considerar os sujeitos escolares que escrevem como um conjunto de sujeitos aprendizes (seria ridículo negar as necessidades de ensinar metodicamente e coletivamente um "corpus de prescrições") e também como um conjunto de autores singulares, o que não quer dizer um conjunto de escritores. Em nossa sociedade, em nossa escola, um homem (uma criança) que pega pincéis e pinta um rosto sobre uma tela está pintando, um homem (uma criança) que pega sua flauta e compõe um trecho, ele faz música, seja qual for sua habilidade artística ou a qualidade final do produto. Mas, um homem (uma criança) que pega sua caneta para escrever uma história não faz literatura. Gérard Genette, em $A$ obra de arte, $A$ relação estética (1997) que é nossa referência central, afirma, ao inverso, que toda ficção narrativa é constitutivamente literatura (o que não prejudica em nada o valor dessa literatura, determinada pelas esferas autorizadas: editores, críticos literários, universitários...), porque ela deriva, como a tentativa do pintor ou do músico aspirante, de uma intenção artística. Sem nos esconder os problemas teóricos que ela pode suscitar, tal visão das coisas tem o mérito de nos permitir pensar o continuum e de a construir didaticamente. Nós chamamos, então, aqui "autor" o aluno que produz um texto narrativo com uma intenção artística e o 
distinguimos do "escritor", que é um autor cuja intenção e o valor ou "mérito" estético foram reconhecidos em um contexto social e histórico dado e que detém status oficializado (por exemplo, consta em um catálogo de editor). Uma vez colocada esta possibilidade teórica, um certo número de príncipios de ação se colocam para a investigação.

\section{Encorajar o aluno a adotar uma postura de autor: algumas condições}

\section{Legitimar esta postura no espaço da classe}

Para um aluno, adotar uma postura de autor é se sentir autorizado a se colocar no espaço da classe: "Eu estou segura que aquele que aprende tem ainda um longo caminho a percorrer para alcançar o domínio da língua e do discurso, mas aprendendo quem eu sou, eu já me posiciono como um autor, investido de um projeto de efeito sobre o leitor com uma intenção artística, independentemente de minhas escolhas enunciativas, narrativas e linguísticas, singulares em minha escrita e em minha sensibilidade, e eu espero que me reconheçam e que me leiam como tal".

Encorajar o aluno que escreve a extrair de sua experiência de leitor de literatura uma tática de escrita e construir mentalmente uma figura de seu "leitor-modelo"

Além da possibilidade de se inscrever nos passos de um escritor (por imitação, farsa...), de mobilizar meios técnicos observados nos textos literários, o autor é aquele que tem o desejo de inscrever sua escrita como lugar único e singular, concebido como um "apelo à liberdade do leitor" (SARTRE, 1948). Ou seja, o jovem adaptador não é possivelmente o autor que inicialmente foi ensinado a analisar sua experiência de leitor de literatura para alimentar sua experiência de escrita e a se perguntar como os textos literários lidos necessitam que "qualquer um [os] ajude a funcionar" (ECO, 1985). A originalidade de nosso trabalho, se há alguma, é explorar uma dimensão nova da interação leitura/escrita. Nós postulamos que, da experiência da leitura literária, os alunos vão poder tirar, além dos saberes narrativos tradicionalmente apontados, os saber-fazer pragmáticos (por que e como envolver o leitor no jogo do texto, solicitar seu investimento afetivo e cognitivo, suscitar sua conivência cultural e sua adesão ao mundo fictício criado?...) e produzir eles mesmos um texto que 
demanda "que alguém o ajude a funcionar". Trata-se então de almejar em classe um Leitor Modelo, de preferência "astuto", como dissemos dos alunos do $4^{\circ}$ ano do ensino fundamental, educado e sensível, "capaz de cooperar com a atualização textual de maneira como ele, o autor, o pensava" e de "implementar uma estratégia da qual fazem parte as previsões dos movimentos do outro" (ECO, 1985). Nesse contexto, este Leitor-Modelo se encarna ou não se encarna entre os leitores concretos (diz-se que uma obra "encontrou ou não encontrou seus leitores"). Assim, a aposta sobre a existência de um Leitor-Modelo exigente pode, portanto, se concretizar em sala de aula:

A partir da sua experiência de leitor, ele tenta reproduzir os efeitos dos escritores que lhe deram a satisfação de serem sentidos por terem se envolvido com o autor no acabamento do texto, pensar por si próprio em "captar" um leitor inteligente, cultivado e sensível, organizar para ele os silêncios que supõe ser capaz de completar, introduzir alusões culturais, jogos de palavras, ambiguidades, indícios que supõe ser capaz de perceber, trabalhando com a beleza das palavras, das frases que supõe ser capaz de desfrutar... (ECO, 1985).

Assegurar-se que a intenção artística do aluno-autor vai responder a uma atenção estética da parte dos leitores reais (professores e pares)

O autor se endereça à liberdade dos leitores para dar existência a sua obra. Mas ele exige também que eles lhe devolvam esta confiança que ele lhes deu, que eles reconheçam esta liberdade criativa nele. $\mathrm{O}$ aluno não é possivelmente autor de fato, somente se ele souber que a sua intenção artística vai provocar na classe uma atenção estética, no professor e entre os seus pares (onde Genette define a relação estética). Somente se ele souber, em suma, que seu texto, fruto de uma liberdade criativa, vai ser objeto de uma leitura semelhante àquela à qual se deve aos autores, uma leitura literária atenta à fabricação do texto, ao grão e ao jogo de palavras, aos espaços livres, à polissemia potencial, à novidade da descoberta narrativa, à emoção suscitada pela narração ou pelo comportamento de tal e tal personagem... e não somente aos erros de ortografia ou de sintaxe. Em outros termos, uma leitura fundamentada sobre um novo pacto, que respeita seus direitos de autor, não convoca somente critérios de avaliação formais construídos coletivamente e impostos a todos, mas com critérios próprios à avaliação de um texto literário singular, que se resumirá assim: "O texto do par se deixa ler como um texto literário de autor, ele deixa ao leitor uma parte do trabalho e provoca um efeito de curiosidade, de suspense e de surpresa?". 
Incitar os alunos a verbalizar seu projeto de autor

O jovem aprendiz somente é autor quando forma com seus pares uma comunidade de autores, convidados a exprimir e a confrontar seus projetos de escrita singulares: suas escolhas narrativas ("Eu escrevi Moi Georges para não escrever na terceira pessoa, para mudar um pouco") $)^{5}$, o que os motiva afetivamente ("Eu coloquei Georges porque eu gosto muito do nome e não é o meu, a história não é verdadeira"), os efeitos esperados, ("Eu não dei as razões da troca, é um mistério, é necessário guardar o mistério para o leitor"), as dificuldades encontradas, as hesitações e os remorsos, o que eles consideram como um sucesso e o que satisfaz o seu ego de autor ("Eu gosto muito da última frase: "eu a vejo arrepiar seus pelos e suas garras de um pouco mais de um centímetro"...)

Em um fórum, onde cada um abre as portas de sua cozinha, a escrita aparece porque ela é: um trabalho de artesão supondo suas escolhas táticas (das quais nem sempre se controlam as consequências: diz-se, escrever é uma aposta), suscetível de proporcionar contentamento pessoal. As receitas de uns podem, bem entendido, inspirar os outros.

Explorar as falhas da relação artística

O aluno que apresenta sua experiência pessoal de escrita, "candidata-se" à relação estética junto aos seus pares investidos da tarefa de "verdadeiros" leitores. Mas, pode acontecer que as intenções do autor não sejam percebidas pelos leitores, porque os meios encontrados para responder à intenção são inadequados (os efeitos programados não se produzem) ou porque os leitores pares não têm a atenção estética requerida ou não estão à altura do Leitor-Modelo visado. Cabe ao professor determinar qual destas razões é a boa, seja no primeiro caso, de remeter ao autor sua falha pragmática, de impulsioná-lo à pesquisa de outros meios na reescrita ou na clarificação de seu projeto artístico; seja no segundo caso, de incitar os pares leitores a apreender esta intenção não percebida, como eles o fariam em uma leitura de um texto literário. Nas trocas, os leitores podem inversamente perceber os efeitos não previstos pelo autor, que pode em seguida decidir apressar o crescimento de seus efeitos em germinação, dos quais ele

5 Nós citamos aqui e nos parênteses seguintes as propostas apresentadas por Kévin, aluno do $4^{\circ}$ ano primário, sobre seu texto. 
não tinha consciência. Em suma, a escrita pode configurar-se de tal forma que "o lugar do acaso e do arbitrário se transforma pouco a pouco em necessidade" (DEBRAY-GENETTE, 1988).

\section{Ensinar a reproduzir comportamentos dos autores}

\section{Modificar a relação com a escrita e com o empréstimo}

Trata-se de modificar as representações correntes que têm os alunos do processo de redação, da rasura, da "inspiração", da "originalidade", da "verdade literária", ou seja:

- Ensinar aos alunos que os autores não são "inspirados", que seus textos não saem todos prontos de suas cabeças antes de colocar as palavras no papel, mas são fruto de um trabalho de escrita/reescrita longo e por vezes tedioso, por onde o que é finalmente escrito, se descobre escrevendo ("Eu escrevo para poder ler o que eu não sabia que ia escrever", diz o escritor Claude Roy; "O que eu encontro que me faz aprender é o que procuro", diz o pintor Soulage), em suma, se não se sabe o que escrever, o que se escreverá se encontrará escrevendo/ reescrevendo.

- Ensinar aos alunos que a rasura não é o sinal de fracasso, mas, bem ao contrário, é sinal de uma perícia ("teu texto necessita ser "polido", "desbastado", "polido até o último botão da polaina", relido e reescrito; "o controle é apenas um lugar da inabilidade" ").

- Ensinar aos alunos que escrever não é fazer uma obra inteiramente original, que todos os autores emprestam uma parte de sua matéria primária aos outros autores para recompô-la e se apropriar dela, e que não se trata de uma "cópia" condenável.

- Ensinar aos alunos que as relações entre realidade e ficção são mais complexas que eles possam crer, que a história de vida não responde ao critério de "literalidade", mas aquele de "literariedade", que implica sempre uma parte de ficcionalização do real e, inversamente, que toda história de imaginação se alimenta de uma parte da realidade.

6 Palavras de Virginia Woolf, no Jornal de um escritor, Paris, Christian Bourgois Editor, 1984.

7 Pascal Quignard, Pequenos tratados 1, Paris, Gallimard, 1997, p. 63. 
Consequentemente, certo número de situações práticas se coloca:

- Propor aos alunos tarefas de escrita complexas, originais e estimulantes. Deixar ao projeto de escrita o tempo para amadurecer: não impor 20 minutos para escrever tão logo a instrução seja apresentada, dar a instrução bem antes e acordar com cada aluno o tempo de escrita/ reescrita que ele julgue necessário para chegar aos seus fins, as necessidades em várias etapas e sobre vários dias.

- Encorajar a pensar a narrativa em "eu" ou em "ele" como uma escolha deliberada (e não como uma coação da realidade: "eu" quando é uma história de vida, "ele" quando é uma história imaginária) que não permite as mesmas possibilidades e tem efeitos diferentes (vejamos o que diz Cyril, aluno do $4^{\circ}$ ano do ensino fundamental: "Há dois personagens em minha história, o tio e eu. Eu teria colocado ele no lugar de $e u$ mas com eu há mais dúvida sobre a verdade. E depois eu poderia ser o tio e eu teria começado por como todos os dias meu sobrinho vinha me ver no lugar de como todos os dias eu ia ver meu tio").

- Encorajar a integrar a sua própria experiência, suas próprias leituras (assim como os textos dos escritores conhecidos e amados), seus conhecimentos escolares em biologia, história, geografia, matemática, à trama da história de ficção (o que nunca os alunos fazem, mas os autores fazem).

Instituir uma caderneta de escritor e incitar a autoprescrição de instruções

Nessa caderneta, o aluno, como os autores, se autoprescreve instruções e faz ensaios de escrita para ele mesmo; ele reúne a documentação de apoio de narrativas projetadas ou em curso de escrever (descrições de monumentos emprestados dos guias turísticos, modo de vida de um animal retirado de um documentário científico...); ele copia, dos livros de literatura infantil ou dos romances lidos, passagens preferidas; ele desenha personagens que somente pedem para ganhar vida; ele transcreve pedaços de diálogos inseridos, escolhe títulos (encontra-se na caderneta de Simon, aluno do $4^{\circ}$ ano do ensino fundamental, estes títulos possíveis: Mister Mistério - O fantasma tricolor - O carneiro que tricotava sua lã - Dois trapaceiros - Suavemente em Ouagadougou - Tâmaras e acrobatas)... Mais amplamente, em sua caderneta, o aluno constrói "seu universo pessoal" material e mental (os objetos, as pessoas, os personagens, as sensações pertinentes a esse universo). 


\section{Ensinar as escolhas de escrita}

Enquanto ensina as normas das quais ele não pode em nenhum caso se eximir, o professor chama atenção sobre as escolhas de escrita encontradas na leitura entre os autores e seus possíveis efeitos: escolha de nomes dos personagens, escolha do narrador, escolha do desenvolvimento das ações ou ao contrário as supressões, começar ou não pelo início da história, organizar uma queda rápida ou retardar o impasse por buscas intermediárias, descrever o personagem no início da história ou no meio de um diálogo, destilar os detalhes à medida das necessidades da ação, resumir as trocas entre os personagens ou desenvolver o diálogo deles. Trata-se de comparar as possibilidades como nos convida aqui, em um pequeno exemplo, Umberto Eco, na Apostila do Nome da Rosa:

Vejamos qual diferença entre estes cinco diálogos:

- Como vai você?

- Nada mal

- Como vai você? diz Jean

- Nada mal e você? diz Pierre

- Como, diz Jean, como vai você?

-E Pierre imediatamente: - Nada mal e você?

- Como vai você? se apressa Jean

- Nada mal e você? caçoa Pierre.

Jean diz: Como vai você?

- Nada mal, responde Pierre, de um caminho incolor.

Depois com um sorriso indefinido: - e você?

Um aluno assim colocado na postura de autor é capaz de dizer, como o narrador de Jacques o Fatalista ("Veja você, leitor, que eu estou em um belo caminho, e que ele teria somente a mim para fazer esperar um ano, dois anos, três anos, a história dos amores de Jacques..."): "Eu sou aquele que tira as amarras."”

8 Para ir além desse artigo, ver Catherine Tauveron e Pierre Sève, 2005. 


\section{Uma pesquisa-descrição sobre as práticas ensinadas em matéria de escrita ou alguns obstáculos para a implementação do apresentado acima}

A pesquisa, descritiva e qualitativa, contando com trinta professores de ensino fundamental e médio, se apoia sobre três tipos de dados:

a - declarações de práticas de professores obtidas a partir de entrevistas orientadas por um questionário padrão;

b - práticas efetivas de ensino de escrita (mas descontextualizadas) solicitadas em torno de um conjunto de tarefas impostas (análise de instruções, análise de produções de alunos em seu estado final ou em suas versões sucessivas, avaliação "como em sala de aula" de cópias dos textos dos alunos, de cenários didáticos);

c-práticas efetivas de escrita (reescrita de um texto de aluno, para apreender como, além de seu julgamento de avaliação e de seus conselhos de reescrita, os professores realizariam eles mesmos a tarefa de reescrita).

Os dados recolhidos permitiram estudos de caso e o estabelecimento de perfis dos professores. Mas no espaço desse artigo, nós percebemos que alguns traços dominantes são os principais obstáculos para a implementação do que nós chamamos de uma "escrita literária" em sala de aula. ${ }^{9}$

Destacamos primeiramente que ensinar a escrita é sem dúvida uma das tarefas mais temíveis, porque o ato de escrever é intrinsecamente complexo, porque não há respostas esperadas a uma instrução dada e, sobretudo, porque o currículo de francês não implica (quase) nenhuma formação para a escrita, trata-se de ensinar o que não se pratica e por vezes o que não se sabe fazer por si mesmo, embora os traços de insegurança principais estejam revelados nos dados coletados. Mas há também certezas. Há que se notar que graus diversos de discursos e práticas são alimentados em uma espécie de cultura profissional intangível (frequentemente separada das realidades sociais da escrita, porque é, sem dúvida, reprodução de experiência escolar), que atravessa as gerações e afeta singularmente a maneira de conceber o processo de redação, a escolha das instruções e o modo de avaliação das cópias. Os professores vivem sobre um legado e sobrevivem provavelmente graças a ele.

9 Encontrar-se-á o resumo quase exaustivo do relatório de pesquisa em TAUVERON, C. (2009), artigo igualmente consultável em http://reperes.revues.org 


\section{O saber dos professores sobre o saber escrever dos alunos e suas consequências}

Os professores entrevistados têm uma representação em comum do ato de escrever, visto como um processo hierarquizado e linear (pensado e previamente construído e depois colocado em palavras). Esta representação clássica é desunida e hierarquizada das operações, e logicamente não integrada à operação de revisão ou integrada somente no fim. Ela é colocada como o modelo de uma escrita especializada: "Para os adultos, vai-se inicialmente fazer um plano com nossas ideias e depois se vai escrever". Tal "modelização" que não pensa a escrita como uma reescrita, mas como um processo fixado para todos os que estão aprendendo a escrever, ela está longe das modelizações psicolinguísticas daquelas que os geneticistas podem inferir em seus estudos de rascunhos de escritores (variabilidade de "perfis" dos escritores e singularmente da sequenciação das operações) e dos testemunhos diretos destes especialistas singulares que são os escritores. Aliás, os professores subestimam em seu conjunto de competências os alunos. Para ajudar os alunos, eles escolhem geralmente adotar o que se chamará de uma política segura, que se caracteriza pelo apagamento ou pelo desvio do obstáculo: atenuar a falta de imaginação suposta e trabalhar apenas sobre o vivido, não perguntar mais que a colocação das palavras em uma trama fornecida e pré-planificada ou solicitar a pesquisa coletiva prévia das "ideias", fornecer o vocabulário, renunciar à reescrita e, acima de tudo, jamais dar tarefas complexas. As instruções a que nós os submetemos, que pediam a execução de uma tarefa complexa e completa de escrita de uma história, como também operações constitutivas de uma escrita literária (a adoção de um ethos discursivo singular, a postulação e definição de um leitor "astuto", a ficcionalisação do "eu") são julgadas fora do campo de possibilidades escolares ("É enorme! Pede-se ao aluno ser narrador, pois ele deve escrever em primeira pessoa, ele deve também se colocar no lugar do leitor que vai ler em seguida.... é muito dificil para os alunos"; "Se eu lhe digo: 'teu narrador está na primeira pessoa', ele vai dizer: 'sou eu'”). Construir seu Leitor-Modelo, considerar o "eu" como um outro fictício, uma máscara atrás da qual se esconder, são operações declaradas a priori inacessíveis pelos alunos. Tem-se aqui um "saber" partilhado sobre o aluno que oculta um saber da experiência, sobre a aptidão muito precoce das crianças para entrar no jogo do faz-de-conta.

Na lógica dos professores, que assimilam o complexo ao complicado, são propostas somente tarefas parceladas, julgadas mais simples. É o caso de todas as tarefas de complementação de um enredo proposto ("escrever um parágrafo de um conto, escrever a continuação, o início ou o meio de uma história"), da 
redação de trechos da história descontextualizados, de espera do roteiro (escrever descrições, escrever diálogos) ou ainda de completar ou transformar uma matéria-prima ("Escreva os pensamentos desse personagem”). Os alunos não são colocados em uma situação de completar simultaneamente a totalidade das operações. A escrita não é pensada e ensinada como uma atividade sistêmica (com regras entre problemas multidimensionais estreitamente e diversamente conectados). Nunca pedindo, ou quase nunca, para se escrever uma história em sua integralidade, elimina-se um fator de risco, mas, sem dúvida também, introduz-se outro involuntariamente: descrever fora do contexto é uma operação mais difícil que em um contexto que impõe a seleção, o ordenamento e a orientação argumentativa dos traços; escrever os diálogos, as descrições fora de contexto, esperando o roteiro, não ensina a escrever as descrições, os diálogos tendo uma funcionalidade em um contexto narrativo; escrever um final de história ou colocar em palavras uma trama narrativa imposta não ensina a planificar um enredo. O objetivo visado, reduzir a insegurança na escrita dos alunos e evitar a página em branco, é alcançado, mas nenhuma competência nova é construída.

\section{O saber-escrever (reescrever) dos professores}

Espera-se de um professor que ele seja capaz de executar as tarefas que dá aos seus alunos. Sintomaticamente, mais da metade dos professores estudados não reescreviam, como lhes era solicitado, o texto problemático do aluno que estava sob sua supervisão. Como observa Marie-Claude Penloup (1999), estudando as concepções (partilhadas) da escrita entre os alunos e seus professores, tudo se passa como se a passagem ao ato da escrita implicasse em uma "exposição" incômoda, um desnudar indecente. Incômodo que se compreende facilmente, mas do qual se constrói a hipótese que não ocorreria se, por acaso, fosse pedido para que redigissem a solução de um problema de matemática. Aqueles professores que aceitaram o desafio tiveram dificuldade de reescrever de maneira satisfatória. Eles introduzem no texto disfunções suplementares, indício que ao não construírem uma representação precisa de seus sucessos ou disfunções, não encontram uma solução alternativa satisfatória. Caso de figura singular, entre o conjunto dos objetos ensinados ou a ensinar, a escrita é aquela para a qual os professores têm menor competência e segurança pessoal. Se eles têm por hábito, antes de confiar uma tarefa aos alunos, verificar a possibilidade de sua execução e construir ao menos mentalmente uma resposta-modelo, nenhuma destas precauções é tomada com relação à escrita (nas palavras de um professor, 
"A escrita, é o único domínio onde, se eu dou a um sujeito, eu não o faço.”). Primeiro porque em matéria de tarefa de escrita, de narrativas singulares, não existe resposta-modelo e, se se pode pensar em um quadro restrito mais ou menos forte para a execução da tarefa, por outro lado restará sempre uma margem importante de liberdade. Pode-se pensar que a insegurança pessoal para escrever se duplica naturalmente em uma insegurança para ensinar a escrever (pode-se ensinar eficazmente e serenamente o que se sabe por si mesmo), ou seja, em um primeiro momento ao menos, faz-se um balanço crítico e detalhado dos sucessos e disfuncionalidades de um texto do aluno e projeta-se as reescritas possíveis.

\section{O saber fazer escrever-reescrever dos professores}

\section{Uma história de um aluno submetido à avaliação}

Trata-se da história de Julie (10 anos e meio), escrita a partir da seguinte orientação (além disso, submetida à avaliação): "Escreva as cenas onde teu narrador encontra uma marionete que ele toma por um ser humano ou uma marionete que ganha vida. Teu narrador fala em primeira pessoa. Escreva de forma que um leitor muito astuto pudesse compreender desde logo o narrador e quem ele é exatamente" (questões que os alunos haviam estudado anteriormente em histórias fantásticas de marionetes ambíguas). Julie retarda a manifestação do fenômeno fantástico, destilando sabiamente os indícios de sua chegada. Ela constrói um suspense e orquestra uma queda, enquanto explica sua escolha de narração dialogada (à moda de um sitcom) organizando cenas, impedindo precisamente a abreviação. Esta escolha é marcadamente calculada: Julie sabe jogar com os detalhes aparentemente insignificantes da conversação cotidiana para construir um efeito real (ao ponto que o conjunto poderia ser encenado sem cessar sem deixar de parecer natural), tanto quanto para diluir a atenção. Ao mesmo tempo, ela não se perde como ocorre frequentemente com as crianças em diálogos intermináveis visando à exaustão: ela sabe parar as sequências de conversação no momento oportuno e construir o encadeamento como uma sucessão de flashes, ela sabe fazer com que o diálogo sirva para construir a progressão de uma trama. A narração dialogada tem outra vantagem: aquela de apresentar fatos brutos, não interpretados pelo narrador e então submetidos somente à interpretação do leitor. Adicionamos que escrevendo para um "leitor muito astuto", conforme solicitado na instrução, ela o obriga a determinar por ele mesmo os atores dos diferentes turnos da fala (não "diz x", de "responde y") e não indica explicitamente as mudanças de lugares, ela provoca a inferência do contexto. 
Este texto de aluno foi escolhido porque escapa dos cânones do texto de aluno que respeita minuciosamente a orientação. Portanto, nós construímos a hipótese de que dois tipos de olhar podiam ser colocados sobre ele: se aceita a ideia de que as crianças podem ter projetos singulares de escrita, pode-se ler um projeto de autor e ali ver escolhas narrativas audaciosas e eficazes; se se considerar a criança como um aprendiz-escritor e que não domina seus meios, o distanciamento da norma escolar pode ser pontuado como uma falha. É precisamente o tipo de olhar dos professores de nosso painel que nos interessa.

\section{A avaliação dos professores: uma atenção estética não encontrada}

À exceção de uma professora que parece ter uma atenção estética ao texto de Julie e apreende o projeto do autor subjacente, duas conduções dominantes puderam ser reveladas: a primeira é uma manifestação de impotência (“É o gênero de texto sobre o qual eu não sei intervir"), a segunda revela aquilo que se chamará de protecionismo normativo, uma maneira encontrada pelos professores em questão para protegerem eles mesmos do espectro do movimento e do plural (o que é bem a narrativa dos fatos), fechando-se nas normas estáveis, mas também de protegerem os alunos de um "erro" sempre possível. Este protecionismo se manifesta de maneira variada:

- pela condenação das iniciativas "induzidas" do aluno: a originalidade do texto de Julie é percebida, mas condenada porque não se espera de um texto do aluno que ele cultive sua singularidade, singularmente foi escolhida a narrativa dialogada, não indicada na instrução ("Ela não ficou na orientação, ela criou uma espécie de... Há muitas coisas que não foram pedidas. Ela criou uma espécie de trama inútil. Há muitas coisas inúteis em relação à instrução de início");

- pela condenação (massiva) do recurso à narração dialogada em nome de uma representação convencionada, à qual se agrega a condenação da falta de transparência imediata ("é preciso se fazer compreender rapidamente"), quando "a completude e a estrita pertinência são raramente normas alcançadas e/ou visadas pelas narrativas literárias.” (BARONI, 2007).

Nessa perspectiva, contra toda a evidência, Julie não teria escrito uma história porque o diálogo é supostamente inapto a fazer avançar a ação: ele não é, com a descrição, mais que uma decoração ou excrescência subsidiária ou parasitária ("Eu procuro um início, um meio e um fim. Situação inicial... as diferentes etapas da história. De qualquer maneira é necessário encontrar as 5 etapas e aqui a gente não as tem. Tem-se apenas diálogo. Não é uma história de fato. O diálogo é uma ferramenta, não é o diálogo que deve fazer a história."). 
Nenhum professor desempenha o papel do leitor "astuto" previsto na orientação: todos sonham com um texto do aluno "transparente", para um leitor preguiçoso. Os critérios formais mobilizados tornam insensível à variação genérica e à variação idiossincrática e tornam impossível, da parte do aluno, toda tentativa de efeito literário.

Constatamos, então, que os leitores professores observados não estão em condição de exercer diante do texto do aluno as mesmas competências (e a mesma bondade) que lhes permite enfrentar a resistência das obras literárias legítimas. Todos são provavelmente bons leitores de literatura que depararam com romances que não respondem de nenhuma maneira ao modelo que eles ensinam, são romances que apresentam exposições incompletas ou retardadas, hipertrofiam a descrição em detrimento da narrativa, que obliteram a situação inicial ou a natureza da complicação, que não liberam a situação final, que, à margem da trama, acumulam as informações de indícios da qual uma das funções é construir o efeito do real.

Romances que solicitam uma forma de questionamento implícita endereçada ao leitor, que, pela reticência que eles introduzem - sua falta de clareza provisória -, tem uma função intrigante, apresentam um enigma criativo de curiosidade, de suspense e de surpresa, conjunto de elementos que se pode reagrupar sob o termo de "tensão narrativa" (BARONI, 2007).

Eles têm, sem dúvida, também como espectadores de filmes, de sitcom ou de teatro encontrado narrações dialogadas, e todas repousam sobre as capacidades do diálogo atuar no papel de vetor da ação. Coloca-se então a questão seguinte: como fazer para que um professor possa reinvestir suas experiências de leitor em seu ensino de escrita, mais exatamente, possa adotar uma postura de leitor de produções dos alunos e critérios de avaliação, em contradição ou em defasagem manifesta com suas experiências de leitor e ensinar uma "ortodoxia", lá onde existe somente uma heterodoxia? Marie-Claude Penloup (2007), colocando-se do lado dos alunos, estudou o que ela nomeou os "conhecimentos ignorados", conhecimentos adquiridos pelo sujeito escolar em sua experiência pessoal, mas não entrando em um corpo de saberes socialmente reconhecidos e institucionalizados e, assim, ignorados pelo sujeito e/ou ignorados pela instituição escolar. Sua reflexão se coloca sobre os meios de identificar estes conhecimentos ignorados, de conscientizar os sujeitos e os envolver em um projeto de aprendizagem. Há simetricamente um conjunto de "conhecimentos experimentais ignorados" pelo sujeito professor (porque recobertos por pseudo-saberes institucionalizados em uma esfera escolar, que chamamos "saberes profissionalizados"). Coloca-se então a questão, que é uma questão de formação, dos meios a encontrar para que estes conhecimentos ignorados possam ser recuperados pelo professor em seu projeto de ensino e articulados a ele. 


\section{REFERÊNCIAS}

BARONI, R. Les nouveaux outils didactiques de la narratologie 'post-classique'. Enjeux $70,2007$.

BARTHES, R. Qu'est-ce que l'écriture? In: Le degré zéro de l'écriture. Paris: Points Seuil, 1953, 1972. p. 7-17.

BAYARD, P. Qui a tué Roger Ackroyd? Paris: Editions de minuit, 1998.

DEBRAY-GENETTE, R. Métamorphoses du récit. Autour de Flaubert. Paris: Seuil, 1988.

ECO, U. Lector in fabula. Paris: Grasset, 1985.

ECO, U. Apostille au nom de la rose. Paris: Grasset, 1985.

GENETTE, G. L'œuvre de l'art, La relation esthétique. Paris: Le Seuil, 1997.

PENLOUP, M. C. L'écriture extrascolaire des collégiens. Paris: ESF, 1999.

PENLOUP, M. C. Les connaissances ignorées. Approche pluridisciplinaire de ce que savent les élèves. Lyon: INRP, 2007.

QUIGNARD, P. Petits traités 1. Paris: Gallimard, 1997.

SARTRE, J.P. Qu'est-ce que la littérature? Paris: Gallimard, 1948.

TAUVERON, C. Pratiques ordinaires du brouillon et de ses entours: quelles références aux pratiques des écrivains? Repères - recherches en didactique du français langue maternelle. Revue de l'Institut National de Recherche Pédagogique. Lyon, n. 40, p. 79-109, 2009.

TAUVERON, C.; SEVE, P. Vers une écriture littéraire ou comment construire une posture d'auteur à l'école. Paris: Hatier, 2005.

TAUVERON, C. (Org.). Lire la littérature à l'école. Paris: Hatier, 2002.

TAUVERON, C. Comprendre et interpréter le littéraire à l'école: du texte réticent au texte proliférant. Repères - recherches en didactique du français langue maternelle. Revue de l'Institut National de Recherche Pédagogique. Paris, n. 19, p. 9-38, 1999.

WOOLF, V. Journal d'un écrivain. Paris: Christian Bourgois Editeur, 1984.

Texto recebido em 18 de fevereiro de 2014.

Texto aprovado em 04 de março de 2014. 
